Working Paper: 03-35

Economic Series 11

July 2003
Departamento de Economía

Universidad Carlos III de Madrid

Calle Madrid, 126

28903 Getafe (Spain)

Fax (34) 916249875

\title{
ON THE INTERACTION BETWEEN EDUCATION AND SOCIAL SECURITY *
}

\author{
Juan A. Rojas ${ }^{1}$
}

\begin{abstract}
This paper uses an overlapping generations model with endogenous fertility choices to analyze the quantitative costs and benefits of subsidizing higher education, paying particular attention to the interaction between such policy and the sustainability of the social security system. The paper focuses on the demographic change as the mechanism that link both policies. It is found that an increase in education subsidies changes the educational composition of the population and lowers average fertility. Lower average fertility and higher life expectancy of educated individuals translates into changes in the age structure of the population that requires an increase in the social security tax rate in order to balance the pension budget. Such process reduces the welfare benefits of this educational policy since the rise in social security taxes lowers the after-tax lifetime earnings of almost all individuals born in the period of the policy reform and over.
\end{abstract}

Keywords: Education Subsidies; demographic change; social security.

JEL Classification: D58; H55; I28; J10

${ }^{1}$ Departament of Economics, Universidad Carlos III de Madrid; E.mail: rojas@eco.uc3m.es

$\left({ }^{*}\right)$ This paper is a revised version of a chapter of my thesis written at the European University Institute. I thank my advisor Prof. Ramon Marimon for his guidance and support. I am also grateful to three anonymous referees and an Editor, G. Bertola, V.V. Chari, Marcel Jansen, A. Marcet, S. Rendon, J.V. Rios-Rull, C. Upper, R. Waldmann and the participants of the EUI Macro Workshop, the XXII Simposio de Analisis Economico (Barcelona), Universidad Carlos III de Madrid and the University of Southampton for helpful suggestions. Some parts of this work were done while visiting the University of Pennsylvania. The hospitality of J.V. Rios-Rull is acknowledged. This research was supported by a DGESIC grant PB98-0139. All remaining errors are mine. 


\section{Introduction}

Public expenditure on social security pensions is expected to grow rapidly between 1998 and the end of the first quarter of the next century. Demographic trends imply a substantial increase in the number of retired people as the baby-boom generation reaches retirement age. This fact has motivated an increasing concern about the sustainability of the pension systems in developed countries. In this sense, the recent research effort on social security has mainly concentrated on the optimallity of the current pay-as-you-go pension system (e.g. Imrohoroglu et al. (1995)) and the design of a feasible reform to a funded system (e.g. Huang et al. (1996)). These studies have a feature that is crucial for the type of questions I want to address in this paper, namely they abstract from the interaction between the financial viability of the social security system and the way other public policies are designed. This is an important shortcoming since abstracting from this interaction may prevent governments from facing the real consequences of the implementation of a policy reform. The purpose of this paper is firstly to investigate the interaction between a policy aimed at subsidizing higher education and the sustainability of the social security system paying particular attention to the demographic change as the critical mechanism that relates both policies. And secondly, to analyze to what extent this interaction affects the quantitative evaluation of the costs and benefits of education subsidies.

With some exceptions, the existing literature has studied the economic effect of both policies (public education and social security) separately. On the one hand, there are some studies that analyze the efficiency gains produced by the investment of public resources in education. The existence of borrowing constraints that prevent young agents from borrowing against future income (Fernandez and Rogerson (1994)) and the possible gains stemming from externalities in the accumulation of human capital (Docquier and Michel (1994)) are examples of this effort. Other studies have stressed the link between education and the optimal number of children, e.g. Barro and Becker (1989) and Becker, Murphy and Tamura (1990). These frameworks could be potentially useful to qualitatively study the interaction between public education and social security. However, these are mostly overlapping generations models where agents live two periods and consequently they cannot incorporate great demographic 
detail. More recently, Heckmann, Lochner and Taber (1999) use a large overlapping generations model with endogenous educational attainment to address the quantitative costs and benefits of tuition subsidies in a general equilibrium framework. This work is more close in spirit to mine, although in their work the demographic characteristics of individuals in terms of mortality risk and fertility are ignored.

On the other hand, many recent studies have identified the aging process as the critical variable that limits the financial sustainability of the social security system in western countries (e.g. European Economy 3, 1996). The work of Auerbach and Kotlikoff (1987) provides a useful framework to quantify the effect of an aging process on the viability of a pay-as-yougo system. However, they assume that the aging process is exogenous to the model and in contrast to Heckmann et al (1999) agents cannot choose their education attainment.

Finally, there are some studies that analyze the interaction between education and social security. Blomm and Kaganovich (2002) have studied the effects of public education on the distributional effects of human capital in an economy with social security. In Ehrlich and Lui (1998) children provide support to parents in old age, so that parents have an interest in the education of their children over and above any altruistic motives. Therefore, it is possible that social security weakens the link between a parent's retirement income and the earnings of his own children (since part of the child's earnings are taxed away to support all elderly persons), thus leading parents to devote fewer resources to educating their children.

In a related work Kaganovich and Zilcha (1999) consider the interaction between public education and the social security. They study a model where altruistically-motivated parents invest in the human capital of their children. When parents retire, the labor income of their children's generation is taxed to finance their social security benefits. This link between the human capital of children and the parents' retirement benefits is disregarded in each parental educational decision, but it is captured by the government's social optimization. They find that for some parameter values the optimal policy entails not only subsidizing education but also to tax labor income to finance retirement benefits. This is the case when agents value very much consumption when old. In this case agents save relatively more, pushing down the equilibrium interest rate. Hence, it is optimal to introduce a pay-as-you-go system because 
the resources invested in the social security system earn a rate of return which is greater than the equilibrium interest rate.

Despite the usefulness of these studies, these are two-period overlapping generations models and consequently are not well suited to give a quantitative answer to the question at hand. In contrast, this paper presents a computable general equilibrium model with the following features. First, at each point in time there are six cohorts differentiated by education, since data shows that the fertility and mortality characteristics of individuals is linked to their educational attainment. Second, the decision whether or not to acquire education is endogenous. This decision is taken in the first period of adulthood. At the end of this period individuals decide how many children to have facing a trade-off between the next period's marginal utility of an additional child (since children enter the utility function) and the cost of rising these children while they are at home. Since educated individuals earn higher wages, the existence of a fixed portion of time per child to be spent in childcaring activities means that the opportunity cost of children is higher for educated individuals and they end up having less children than unskilled individuals in equilibrium. Consequently, apart from any change in fertility decisions, any change in the educational composition of the population can potentially generate a demographic change through a pure compositional effect that changes average fertility.

To perform the quantitative analysis the model economy is calibrated to match some features of the Spanish economy. The study of this economy is interesting because from 1980 to 1993 the percentage of GNP spent on higher education has more than doubled, allowing for a greater share of the population to enrol in university education. On the other hand, the Spanish population is aging very rapidly as compared with the rest of European countries mainly due to the fall in average fertility (see Table 1) and this process is raising concern about the financial viability of the social security system in the near future. These facts suggest that the Spanish economy provides an interesting case to study the interaction between the educational policy and the social security system. Notice that in the model economy the finances of the social security system are going to be affected by the change in the age structure of the population which depends on the equilibrium response of the enrolment in 
higher education to the increase in education subsidies. For this reason, in order to obtain reliable quantitative answers, a well specified general equilibrium framework is needed so as to allow agents to take into account the effect associated with the change in skill prices along the transitional dynamics between steady states. In this framework, the experiment performed in this paper is the following. The initial condition is a model economy characterized by a $0.27 \%$ of GNP spent in subsidizing higher education and an enrolment rate in college of around $21 \%$ in 1980 . In order to obtain an initial asset distribution it is assumed that the economy is in a steady state. Consequently, the educational partition of older age groups is also $21 \%$, and the initial age structure of the population is the one generated by that educational partition. The experiment considered is a policy reform aimed at increasing permanently the percentage of GNP spent on subsidizing higher education (financed with income taxes) from $0.27 \%$ to $0.82 \%$ in 1993 while adjusting the social security tax rate so as to keep the government budget constraint balanced in each period. Finally, we evaluate how the interaction between higher education subsidies and the implied dynamics of the social security tax rates affects the evaluation of the quantitative costs and benefits associated with the educational reform implemented.

The results are the following. In the baseline experiment, it is found that more than doubling the percentage of GNP spent on higher education, with the corresponding increase in income taxes needed to finance it, increases the percentage of the young population that attends college from $20.66 \%$ in 1980 to $31.13 \%$ in $1995,30.09 \%$ by 2010 and $30.69 \%$ in the new steady state. As the educational attainment of the working force improves in the initial periods of the transition, taxable labor earnings increase allowing for a decline in the social security tax rate needed to balance the pension budget from the initial value $29.91 \%$ to $27.37 \%$ in period 2. By period 3 of the transition, the better educated generation of individuals (born in period of the policy reform) start retiring. Since this generation is composed by a higher proportion of skilled individuals, the pension expenditure increases as skilled workers qualify for higher pensions and the social security tax rate has to be rised. In addition, since the demographic behavior of individuals is crucially affected by their educational attainment, as a greater proportion of the population attends college the average number of children 
per women falls from 2.7 to 2.4 by the third period of the transition and the average life expectancy increases. Both mechanisms drive up the old dependency ratio from 0.194 in 1980 up to 0.227 in the seventh period of the transition. The aging of the population and the rise of the social security effective replacement ratio, requires an increase in the tax rate needed to balance the pension budget from $29.91 \%$ in 1980 to more than $34 \%$ in some periods of the transition and $31.71 \%$ in the final steady state.

In order to analyze the quantitative costs and benefits of the increase in education subsidies I follow Heckman, Lochner and Taber (1999) and report for each generation and each type of agent the present value of lifetime earnings and utility attained. The measure of earnings is reported in different scenarios which include: (1) the measure of earnings with the initial income tax, social security tax rate and education subsidy, (2) the earnings when added the new income tax rates, (3) the earnings with the new income tax and the new social security tax rates and (4) the earnings when added the new education subsidies to measure (3). Finally, it is reported the lifetime utility at birth for each generation and type of agent (5). The main results are the following. By generations, most of the individuals already living at the time of the policy reform are those who are negatively affected by such policy change, since they attain a lower consumption profile as their income is taxed to finance the increase in education subsidies. On the benefit side, the individuals born when the policy reform is implemented and over are better off in terms of utility. The reason is that skilled workers enjoy a smoother consumption profile since borrowing constraints are less binding, and unskilled workers earn higher after-tax earnings. This utility gain is particularly higher for those individuals born in the initial periods of the transition. However for those individuals born in the fourth period of the transition and over, this gain is substantially reduced due to the loss of lifetime earnings associated with the rise of the social security tax rate that occurs over the adjustment between steady states. In particular, our results show that the rise of the social security tax rate makes skilled and unskilled individuals born in period six of the transition loose up to more than 10000 and 7000 euros of 1980 of lifetime earnings respectively. To put this figure into perspective, these numbers represent a $3.7 \%$ and $6.3 \%$ of lifetime earnings of the initial steady state (1980) for each type of agent. 
The rest of paper is organized as follows. The next section presents the model. Section 3 presents the calibration of the model. Section 4 discusses the main findings of the paper. Section 5 performs additional experiments and Section 6 concludes the paper.

\section{The Model}

The economy consists of ex-ante homogeneous agents living for $I$ periods of equal length. Each agent is endowed with 1 unit of time that can be allocated to work, education or childcare activities. Upon arrival at the age of $I_{A}$ (the first period of adulthood) each agent starts taking decisions. Let denote $i$ and $j$ the age and type of an agent respectively. The first decision is whether to participate in the labor market as a skilled or an unskilled worker. If it chooses to be skilled it has to devote a fraction $0<g_{i j}<1$ of period $I_{A}$ attending school. I assume that this schooling period is given and common for all agents that choose to be skilled, otherwise $g_{i j}=0$. The remaining time can be devoted to work as unskilled worker. These considerations imply that at each point in time there is a fraction $\phi_{i, t}$ of agents in age $i$ that are skilled. Notice that this fraction is to be determined as part of the equilibrium of the model. Consequently agents are homogeneous until they reach adulthood and are indexed only by age $i \in\{1 \ldots I\}$ and after this age, agents are indexed by age and type $j \in\{s, u\}$ (skilled or unskilled), where the share of age-i type-s individuals in the population is $\mu_{i, s, t}=\phi_{i, t} \mu_{i, t}$ and the share of type-u individuals is $\mu_{i, u, t}=\left(1-\phi_{i, t}\right) \mu_{i, t}$.

\subsection{Demographics}

Each type of agent reproduces according to a fertility schedule $b_{j, t}$ at the end of the first period of adulthood $I_{A}$ taking into account that children are costly but also give utility while they are at home i.e. if $i<I_{A}$. This fertility schedule is different across skilled and unskilled agents and is optimally chosen by individuals. The probability of surviving between age $i$ and age $i+1$ for each type is $s_{i j}$. Hence the unconditional probability of reaching age $i$ is

$s_{j}^{i}=\prod_{k=1}^{i-1} s_{k j}$. The next period share of newly born agents $\mu_{1, t+1}$ is given by (see Rios-Rull (1994) for the one-type stochastic version), 


$$
\begin{gathered}
\mu_{1, t+1}=\frac{1}{1+n_{t}} \sum_{j} b_{j, t} \mu_{I_{A}, j, t} \text { and } \\
\mu_{i+1, j, t+1}=\frac{s_{i, j} \mu_{i, j, t}}{1+n_{t}}
\end{gathered}
$$

where the gross population growth rate evolves according to

$$
1+n_{t}=\sum_{j} b_{j, t} \mu_{I_{A}, j, t}+\sum_{i=1}^{I-1} \sum_{j} s_{i j} \mu_{i, j, t}
$$

\subsection{Preferences}

At each point in time agents are assumed to maximize lifetime utility. Hence the problem of the typical agent that at $t$ has age $i=v\left(v \geq I_{A}\right)$ and type $j$ is to choose consumption from ages $I_{A}$ to $I$ and the number of children $b_{j, t}$ at age $I_{A}$ to solve the problem

$$
\operatorname{Max} \sum_{i=v}^{I} \beta^{i-v} s_{j}^{i} U\left(c_{i, j, t+i-v}, \chi_{i} b_{j, t+i-v-1}\right)
$$

subject to the following period-by-period constraint

$$
\begin{gathered}
a_{i+1, j, t+1} s_{i j}=(1+r(1-\tau)) a_{i, j, t}+y_{i, j, t}-c_{i, j, t}-m_{i, j, t} \\
a_{i+1, j, t+1} \geq 0, a_{1, j, t}=0, a_{I+1, j, t+1}=0,
\end{gathered}
$$

where $\chi_{i}$ is an indicator function that takes value 1 if the agent has age $i=I_{A}+1$ and 0 otherwise. This simply means that individuals enjoy the companionship of the children they had in the first period of adulthood $I_{A}$ only while these children are at home, i.e. when adults have age $I_{A}+1$ or equivalently when children are of age $i<I_{A}$.

The discount parameter is $\beta$, and is assumed to be the same for all agents. Borrowing is not possible and agents accumulate asset holdings to smooth consumption over time. $r$ is the 
interest rate which is exogenous to the model due to the small open economy assumption, $a_{i+1, j, t+1}$ denotes next period asset holdings, $y_{i, j, t}$ is labor income net of taxes plus transfers, $\tau$ is a proportional income tax and $m_{i, j, t}$ is expenditure in child-related goods. Notice that the formulation of the budget constraint of the agent implies the existence of annuity markets. The only reason to assume this is to avoid the issue of what to do with the assets accumulated by those agents who die.

In this economy the cost of rearing children has two components. Agents only have to incur these costs until the children reach adulthood. The first component is associated with the consumption of physical resources $m_{i, j, t}$. A child of age 1 whose parent is of type $\mathrm{j}$ is allowed to consume $v c_{i, j, t}$, where $c_{i, j, t}$ is the consumption of an adult of age $i$ and type $j$, and $v$ is some constant between 0 and 1 . Hence an agent of age $i$ and type $j$ has to spend in children consumption the following amount of resources,

$$
\begin{array}{cc}
m_{i, j, t}=c_{i, j, t} b_{j, t-1} v & \text { if } i=I_{A}+1 \\
m_{i, j, t}=0 & \text { if } i \neq I_{A}+1
\end{array}
$$

In addition an agent has to spend a fixed amount of time caring for its children. If at each point in time an agent is endowed with one unit of time then the total time spent in child-caring activities is

$$
\begin{array}{cc}
p_{i, j, t}=b_{j, t-1} z & \text { if } i=I_{A}+1 \\
p_{i, j, t}=0 & \text { if } i \neq I_{A}+1
\end{array}
$$

where $z$ is the fraction of time an agent has to spent caring for a child of age 1.

Hence, formally the labor supply of an agent is

$$
h_{i, j, t}=\left(1-p_{i, j, t}-g_{i, j}\right)
$$

Let $e_{i, j}$ be the efficiency index, $\tau_{s s, t}$ the social security proportional tax, $d_{i, j, t}$ the social security benefits that are zero if $i<I_{R}$ and $d_{i, j, t}$ otherwise. $T_{i, j, t}$ is the education subsidy 
which is a positive quantity if an agent of age $I a$ attends school and zero otherwise and finally $w_{i, j, t}$ denotes real wages, that are indexed by age and type due to the fact that skilled agents work as unskilled workers while getting education. These considerations allow us to define the labor income net of taxes plus transfers as

$$
y_{i, j, t}=w_{i, j, t} e_{i, j} h_{i, j, t}\left(1-\tau-\tau_{s s, t}\right)+d_{i, j, t}+T_{i, j, t}
$$

\subsection{Government}

The government levies a proportional social security tax on labor income $\tau_{s s, t}$ to finance a benefit of $d_{i, j, t}$ per retiree. This system is assumed to be self-financed, i.e.

$$
\sum_{i=I_{A}}^{I_{R}-1} \sum_{j} \mu_{i, j, t} w_{i, j, t} h_{i, j, t} e_{i, j} \tau_{s s, t}=\sum_{i=I_{R}}^{I} \sum_{j} \mu_{i, j, t} d_{i, j, t}
$$

where benefits are computed applying a legal replacement rate to an average of past earnings up to a maximum pension limit. Hence in age $I_{R}$ benefits are given by,

$$
d_{I_{R}, j, t}=\frac{r e p}{1+\lambda} w_{a v, j, t-1}
$$

where $\lambda$, rep and $w_{a v, j, t}$ are the productivity growth, the legal replacement rate and some average of past earnings respectively. From $I_{R}+1$ to $I$, the pension benefit will be normalized by productivity growth $(1+\lambda)$ and can be updated by a factor $(1+\alpha)$ so that

$$
d_{i, j, t}=\frac{(1+\alpha) d_{i-1, j, t-1}}{1+\lambda}
$$

The government also levies a proportional tax on capital and labor income $\tau$ to finance a per capita education expenditure $E_{t}$ and government consumption $G_{t}$ such that

$$
\sum_{i=I_{A}}^{I} \sum_{j} \mu_{i, j, t} \tau\left(r a_{i, j, t}+w_{i, j, t} h_{i, j, t} e_{i, j}\right)=E_{t}+G_{t} .
$$




\subsection{Production Technology}

Firms rent factors of production in efficiency units from households and produce according to the following concave production function, where $S_{t}$ and $U_{t}$ denotes skilled and unskilled labor respectively

$$
Y_{t}=F\left(S_{t}, U_{t}\right)
$$

\subsection{The Equilibrium}

In this economy a Competitive Equilibrium is a list of sequences of quantities $c_{i, j, t}, a_{i, j, t}$, $b_{j, t}, d_{i, j, t}, \mu_{i, j, t}, \phi_{i, t}, S_{t}, U_{t}, T_{i, j, t}$ prices $w_{s, t}, w_{u, t}$ and social security tax rates $\tau_{s s, t}$ such that at each point in time $t$ :

1) firms maximize profits setting wages equal to marginal products,

$$
\begin{aligned}
& w_{s, t}=F_{S}\left(S_{t}, U_{t}\right) \\
& w_{u, t}=F_{U}\left(S_{t}, U_{t}\right)
\end{aligned}
$$

2) agents maximize the lifetime utility function subject to the period budget constraint taking the education subsidies, wages and taxes as given. In addition the equilibrium ex-ante total lifetime utility levels associated with different lifetime choices at age $I_{A}$ have to be equal,

$$
V_{I_{A}, s, t}=V_{I_{A}, u, t}
$$

3) the equilibrium quantities reproduce the aggregate law of motion of the population (1), (2) and (3),

4) market clearing conditions for each type of labor,

$$
S_{t}=\sum_{i=I_{A}+1}^{I_{R}-1} \mu_{i, s, t} e_{i, s} h_{i, s, t}
$$




$$
U_{t}=\sum_{j} \mu_{I_{A}, j, t} e_{I_{A}, j} h_{I_{A}, j, t}+\sum_{i=I_{A}+1}^{I_{R}-1} \mu_{i, u, t} e_{i, u} h_{i, u, t}
$$

5) and the budget constraint of the government is satisfied period by period.

\section{Calibration}

Agents reach adulthood at 15 and can live up to age 89, after which death is certain. Each model period is taken to be 15 years, consequently there are six cohorts at each point in time. Borrowing is not possible but agents can accumulate asset holdings to smooth consumption over time. Individuals with different educational attainment are different in terms of their death probabilities. Since there is only data on age specific death rates for the entire population in 1980 (taken from the Spanish National Institute of Statistics), I have taken the average individual in the population that has around 10 years of formal education and used the work of Elon and Preston (1996) for the US economy that have estimated that adding one year of education decreases by $2.5-3 \%$ the ratio between the age specific death rate and the age specific survival probability. Consequently the observed mortality profile is adjusted downwards for skilled agents (with 17 years of schooling) and upwards for unskilled ones (with 9 years of education). The results implies a life expectancy at birth of 69.78 and 67.23 years for skilled and unskilled individuals respectively, while the weighted average for the entire population is 67.70 .

The age-dependent productivity profile is computed using data from the Household Panel of the European Union. This is computed taking the average weekly earnings of each educational group across different ages, and then normalizing with respect to the average of the sample. The percentage of household consumption going to children follows the OECD scale, where each adult has a weight of 1 and each children has a weight of 0.5 (see Ringen (1991)). Child care weights are taken from Denton and Spencer (1988). They compute these weights such that once applied over the age specific fertility rates, they can generate an age specific labor force participation profile which is roughly consistent with data. This yields $0.3,0.12$ 
and 0 for a child aged $0-4,5-9$ and 10-14 respectively. Consequently since in the model economy a period corresponds to 15 years, the average time an agent would have to spent caring for each child aged $0-14$ is 0.14 of the period. I use a slightly higher value 0.2 in order to account for the potential earnings loss associated to the depreciation of human capital while individuals stay at home caring for its children. The proportion of time that an agent has to spent attending college is as follows. Unskilled agents start working when they are 15 years old. Those agents who choose to attend the university have to spend until age 22 in schooling activities, i.e. when aged 15-29 they spent 0.533 of the period in schooling activities. These numbers closely capture the Spanish case. Finally, individuals benefit from public expenditures on higher education only by that part corresponding to direct transfers, e.g. grants. This amounts to $4.6 \%$ and $12.3 \%$ of the total public expenditure in higher education in 1980 and 1993 respectively.

Production takes place using labor in efficiency units and the production function is CES in the two types of labor with an elasticity of substitution of $1 / \rho$.

$$
Y_{t}=\left(\gamma H_{t}^{1-\rho}+(1-\gamma) L_{t}^{1-\rho}\right)^{\frac{1}{1-\rho}}
$$

The inverse of the elasticity of substitution $\rho$ is 0.25 as in Canova (1997) which is also in line with the estimates of the empirical literature (Freeman, 1987). The share parameter $\gamma$ is set such that the value of the elasticity of substitution and the marginal productivity conditions of a CES production function generates a skill-to-unskill wage ratio around 2.2 which is the corresponding wage ratio in the Spanish economy in 1980 (Source: Anuario Estadistico de Espana). This target is also in line with the recent empirical work of Bover, Bentolila and Arellano (2000). The estimated $\gamma$ is then 0.615 .

The pension system is calibrated to capture the main features of the Spanish Social Security System in 1980. In particular, pension benefits are computed applying a legal replacement rate to the average of earnings of the five years before retirement. This replacement rate is $100 \%$ if a worker has contributed more than 35 years to the system and pension benefits are updated by the growth of productivity. The income tax rate $\tau$ is set to reproduce the average ratio of government consumption (excluding expenditures in higher education) to 
national income in the period 1978-1995 which is around 0.157 . Notice that the total income tax faced by individuals is the sum of 0.157 and the corresponding ratio of expenditures in higher education over national income in each experiment being equal to $16 \%$ in the initial steady state and $16.62 \%$ after the educational reform.

Due to the small open economy assumption the interest rate is exogenously given and set equal to $2.8 \%$ which is the average annual pre-tax real interest rate in the period 1975-1996 faced by the Spanish economy. The discount factor $\beta$ is chosen such that the implied wealth-to-labor ratio of the model economy generates an interest rate close to $2.8 \%$ using a Cobb-Douglas production function, with capital share parameter 0.347 and an annual depreciation rate $8 \%$ (see Licandro and Puch (1997) for a discussion of this parameters in the Spanish economy). The discount parameter that satisfy this restriction is $\beta=0.993$. The implied wealth to output ratio implied by these numbers is 3.051. The yearly rate of growth of Spanish per capita consumption between 1964-1995 was $2 \%$ and is the value used for the annual growth rate of productivity $\lambda$ in the model economy.

The utility function is assumed to be the constant relative risk aversion function

$$
u(c, b)=\frac{1}{1-\sigma}\left(\theta c^{1-\mu}+(1-\theta) b^{1-\mu}\right)^{\frac{1-\sigma}{1-\mu}} .
$$

Notice that $\mu$ is the inverse of the intratemporal elasticity of substitution between consumption and children, and measures the relative strengh of the substitution and income effect associated to higher wages, consequently this parameter can be used to generate a targeted differential fertility behavior between skilled and unskilled individuals. Hence, the inverse of the elasticity of substitution $\sigma$, the share of consumption $\theta$ and the inverse of the intratemporal elasticity of substitution $\mu$ are set such that the initial steady state of the model economy that is intended to represent the Spanish economy in 1980, matches the following three relationships:

- In Spain the enrollment rate in university education was 21\% in 1980.

- An average number of children per women of 2.7, or 1.35 per individual, which is the average fertility rate for the period 1950-1980. 
- A ratio between the fertility of unskilled individuals to the fertility of skilled ones of 1.64 (Spanish Population Census 1991).

The values implied by these restrictions are $\sigma=1.2, \theta=0.63$ and $\mu=0.8$.

\subsection{Computation Method}

The computational procedure used to solve for the transitional dynamics of the model follows Auerbach and Kotlikoff (1987) and it is an iterative technique often referred to as the GaussSeidel method. Notice that since the economy undergoes a transition in which conditions change over time and economic agents are assumed to take into account future prices in determining their behavior, it is necessary to solve simultaneously for equilibrium in all transition years. In order to implement the computational procedure I assume that the final steady state is reached in 60 model periods, and I have checked that it was not binding. The main steps of the algorithm are the following.

1) Given initial conditions of the asset holdings $\left\{\left\{a_{i, j, t}\right\}_{i=I_{A}}^{I}\right\}_{t=0}$, the age structure of the population $\left\{\left\{\mu_{i, t}\right\}_{i=I_{A}}^{I}\right\}_{t=0}$, and the educational partition of the existing population $\left\{\left\{\phi_{i, t}\right\}_{i=I_{A}+1}^{I}\right\}_{t=0}$, then provide a guess of the path of the equilibrium enrolment rate from $t=1$ to $t=60$, $\left\{\left\{\phi_{i, t}\right\}_{i=I_{A}}\right\}_{t=1}^{60}$.

2) Guess a path for the per-student education subsidy $\left\{T_{i, j, t}\right\}_{t=1}^{t=60}$ and fertility $\left\{b_{j, t}\right\}_{t=1}^{60}$.

- Using $\left\{\left\{\phi_{i, t}\right\}_{i=I_{A}}^{I}\right\}_{t=0}^{60}$, and the age specific fertility and mortality rates, compute the path of the age structure of the population $\left\{\left\{\mu_{i, t}\right\}_{i=I_{A}}^{I}\right\}_{t=1}^{t=60}$.

- Using $\left\{\left\{\phi_{i, t}\right\}_{i=I_{A}}^{I}\right\}_{t=0}^{60},\left\{\left\{\mu_{i, t}\right\}_{i=I_{A}}^{I}\right\}_{t=0}^{t=60}$ and the implied age specific labor effort $\left\{\left\{h_{i, j, t}\right\}_{i=I_{A}}^{I r-1}\right\}_{t=1}^{t=60}$ compute the labor input $\left\{U_{t}\right\}_{t=1}^{t=60}$ and $\left\{S_{t}\right\}_{t=1}^{t=60}$.

- Using $\left\{U_{t}\right\}_{t=1}^{t=60},\left\{S_{t}\right\}_{t=1}^{t=60}$ and the marginal productivity conditions, compute wages by type $\left\{w_{s, t}\right\}$ and $\left\{w_{u, t}\right\}$. 
- Using $\left\{\left\{h_{i, j, t}\right\}_{i=I_{A}}^{I r-1}\right\}_{t=1}^{t=60},\left\{w_{u, t}\right\}$ and $\left\{w_{s, t}\right\}$, compute pension benefits to which agents qualify $\left\{\left\{d_{i, j, t}\right\}_{i=I_{r}}^{I}\right\}_{t=1}^{t=60}$ and the necessary social security tax $\left\{\tau_{s s, t}\right\}_{t=1}^{t=60}$ to keep balanced the pension system.

- Solve the consumer problem in asset holdings $\left\{\left\{a_{i, j, t}\right\}_{i=I_{A}}^{I}\right\}_{t=1}^{t=60}$.

- Using the intramarginal optimal conditions of the consumer problem, compute a new guess of fertility decisions $\left\{b_{j, t}\right\}_{t=1}^{60}$.

- Using the distribution of asset holdings, the labor effort and the income tax rate $\tau$, then compute a new guess for the per-student education subsidy. If the

path of education subsidies and fertility are equal to the guessed ones in step 2) then go to step 3). Otherwise update the guesses, go back to step 2) and repeat until convergence is achieved.

3) Using the equilibrium consumption allocations compute the expected lifetime utility at age $I_{A}$ for each type of agent and time $V_{I_{A}, s, t}$ and $V_{I_{A}, u, t}$. If for all $t V_{I_{A}, s, t}=V_{I_{A}, s, t}$, then the algorithm is stopped. If not, then update the guess on $\left\{\left\{\phi_{i, t}\right\}_{i=I_{A}}\right\}_{t=1}^{60}$ following the rule: if $V_{I_{A}, s, t}>V_{I_{A}, s, t}$ then try with a higher $\phi_{I a, t}$, and if $V_{I_{A}, s, t}<V_{I_{A}, s, t}$ then try with a lower $\phi_{I a, t}$; and go back to step 1).

\section{Findings}

The initial steady state of the model economy has been calibrated to match some features of the Spanish economy in 1980. This year has been chosen for several reasons. First, it is a year for which there is data on wages by educational categories and consequently it is possible to target an empirical wage premium. Second, from the 60 s to the 80 s the percentage of GNP spent on higher education has fluctuated around a value 0.3\%. From 1980 to 1993 the public resources spent on financing higher education has more than double from $0.27 \%$ to $0.82 \%$. Hence, 1980 represents an interesting starting point to analyze the quantitative costs and benefits of an educational reform of this type. In particular, the kind of policy reform I analyze is a permanent increase in the percentage of GNP spent on higher education from 
$0.27 \%$ (1980) to $0.82 \%$ (1993) while adjusting the social security taxes so as the government engages in a period by period balanced budget.

\subsection{General Features}

In the calibration procedure I have targeted the enrolment rate in higher education in 1980, i.e. $20.66 \%$ of the age group $18-22$. In the initial steady state this is also the educational partition of older age groups of the population. Given the differential fertility and longevity between skilled and unskilled individuals, the induced age structure of the population generated by the enrolment rate in college of the initial steady state is slightly younger than the age structure in 1980 of the data (see Table 2). In particular, in the initial steady state the share of the age groups $(0-14),(15-59)$ and $(+60)$ are $33.50 \%, 55.66 \%$ and $10.85 \%$ respectively. In 1980 the age groups of the Spanish population were $25.64 \%, 58.77 \%$ and $15.59 \%$. One reason that can explain this divergence is that in the model economy fertility is concentrated in one age group 15-29 while in the data fertility also takes place at older age groups and delayed fertility usually translates into an older population.

The general effects of an increase in the percentage of GNP spent on higher education from $0.27 \%$ to $0.82 \%$ are the following (see Table 3 ). The existence of a borrowing constraint prevents skilled agents from borrowing against future income to finance consumption when young. Then, an increase in the resources spent in subsidizing education allows them to have a smoother intertemporal consumption allocation since the borrowing constraint is less binding. This increases the expected utility of attending college and rises the enrolment in higher education from $20.66 \%$ in 1980 to $31.13 \%$ and $30.09 \%$ in the first (1995) and second period (2010) of the transition respectively. The enrolment rate in Spain was around $45 \%$ in 1995, consequently the model is underestimating the real behavior of the enrolment rate at universities. A possible reason that could explain this difference is the ongoing skill biased technical change that is affecting western countries. A possibility that is explored later on in this paper. The maximum enrolment rate $31.38 \%$ is reached by the period 5 of the transition and then it smoothly falls until it settles in the new steady state value at $30.69 \%$.

To further understand the changing profitability of the investment in education I have com- 
puted the rate of return of schooling from a lifetime perspective of a young individual living in the initial steady state. In particular, the rate of return on schooling is computed as the internal rate of return that equates the forgone earnings of the educational period to the expected benefits to be received in the form of higher earnings in the future. In the initial steady state this yields a value $17.61 \%$ in annual terms. Absent any change in wages, an increase in education subsidies would increase the rate of return to schooling up to $18.37 \%$ since now the forgone income during the educational period is lower. However, once we account for the general equilibrium effect of reduced wages, the rate of return decreases as compared to the initial steady state up to $16.42 \%$. Meaning that as more agents educate and the wage premium falls then the profitability of the educational choice is reduced.

As the proportion of the population that attends college increases over the initial periods of the transition there is a small increase in the social security tax rate due to the temporary decay in the participation rate (since a higher proportion of the young population is in the schooling period). This is also the reason why per-capita output (see Figure 1) slightly decreases in period 0 . By period 1 of the transition the educational attainment of the working force improves and consequently taxable labor earnings increase allowing for a decline in the social security tax rate needed to balance the pension budget from the initial value $29.91 \%$ to $27.37 \%$ by period 2 . This effect is partially compensated by the decline in the wage premium. In fact as it will be analyzed later on in this section, in the partial equilibrium case with fixed wages, the fall in the social security tax rate in the initial periods of the transition is more pronounced. By period 3 of the transition, the better educated generation of individuals (born in period of the policy reform) start retiring. Since this generation is composed by a higher proportion of skilled individuals, the pension expenditure increases as skilled workers qualify for higher pensions and the social security tax rate has to be increased. Again, this is partially compensated by the fact that as the wage premium is lower, the pension level to which skilled (unskilled) individuals qualify for is lower (higher) than in the initial steady state.

(Insert Figure 1 here)

In addition, as the skill premium falls educated individuals increase fertility both in the short 
and long run since the opportunity cost of children in terms of forgone earnings is lower. Unskilled individuals, react to the higher wages by having less children in the initial periods of the transition although in the long run their fertility stays roughly constant. The reason that explains this fact is the increase in the social security tax rate that lowers after-tax earnings. In fact, in the next experiment without changing the initial age structure of the population the social security tax rate is virtually constant in the long run, and consequently, the fall in the skill premium induces unskilled individuals to have less children in equilibrium. Overall, the model predicts that after the increase in education subsidies average fertility falls from 1980 to 2025 a pattern that is consistent with the recent fertility behavior in Spain, although the model underestimates the fall in fertility observed in the data. For instance, in Spain average fertility felt from 2.67 in 1977 to 1.25 by 2001. In the long run average fertility falls, a behavior driven by the change in the educational composition of the population. This fertility dynamics and the fact that skilled individuals live longer means that the increase in the proportion of the population that attends college translates into a change in the age structure of the population. In particular, over the adjustment path between steady states the old dependency ratio remains constant until the second period of the transition (2010) (since the fall in fertility only affects the age structure of the population with a delay) and increases monotonically from 0.194 to 0.228 in the seventh period of the transition, declining afterwards until it reaches its long run value. This mechanism associated with the aging of the population requires additional increases of the social security tax rate in order to balance the pension budget from $29.91 \%$ in the initial steady state to $34.28 \%$ by the seventh period of the transition. In the long run, the educational composition of the population is constant and is characterized by a $30.69 \%$ of skilled individuals. Associated with the higher relative supply of skilled workers, the wage premium changes from 2.21 in the initial steady state to 1.94 in the final one. In addition, the social security tax rate experiences a long run increase. The reason is that the long run change in the educational composition of the population induces a long-run change in the age structure of the population (through lower average fertility and higher life expectancy) by increasing the relative share of older groups over the total population. In particular, the share of agents aged $0-14$ falls from $33.50 \%$ to 
$32.38 \%$, the share of those aged $15-59$ increases from $55.66 \%$ to $55.99 \%$ and the proportion of the population aged +60 rises from $10.85 \%$ to $11.63 \%$. These results indicate that the ratio between the retired population and the population in working age increases from 0.194 to 0.21 between steady states and requires an increase of the social security tax rate from $29.91 \%$ in the initial steady state to 31.71 in the final one.

\subsection{Cost-Benefit Trade-offs}

I order to analyze the quantitative costs and benefits of the increase in education subsidies I follow Heckman, Lochner and Taber (1999) and report for each generation and each type of agent the present value of lifetime earnings and utility attained (see Table 4 and 5). The measure of earnings is reported in different scenarios which includes: (1) the measure of earnings with the initial income tax, social security tax rate and education subsidy, (2) the earnings when added the new income tax rates, (3) the earnings with the new income tax and the new social security tax rates and (4) the earnings when added the new education subsidies to measure (3). These measures have been computed using the after tax interest rate of the initial steady state in pesetas of 1980 and then converted to euros. Finally, the last measure (5) reported is lifetime utility at birth. In what follows, each generation is labeled by the model period in which they are born (start taken decisions). So that, generation 0 refers to those individuals born in the period of the policy reform, generation -1 refers to individuals born one period before the policy reform and so on.

On the benefit side, the first generation as a whole that can take advantage of the higher education subsidies is generation 0 which is the period in which the policy reform is implemented. Notice that the increase in the proportion of the population that attend college brings about a decline in the wage premium. The financial effect of this process can be seen by looking at the evolution of the present value of lifetime earnings for both types of agents. Absent the effect of new income and social security taxes and the new education subsidies, discounted earnings of skilled agents fall and discounted earnings of the unskilled ones rise along the transition between steady states. The net financial position of individuals is the following. Unskilled individuals born in period 0 and over end up with higher after-tax discounted earn- 
ings than in the initial steady state. For instance, unskilled individuals born in period 6 may gain up to 7000 euros (net of taxes) with the educational reform than without it. In addition, the financial benefits of education subsidies for the generation of skilled individuals born in the period of the policy reform (period 0) and afterwards, is shown in the fourth column of Table 4 that reports the effect of adding the new education subsidy to the present value of net-of-tax lifetime earnings. For instance, skilled workers born in the first and second period of the transition receive 539 EUR and 600 EUR more in education subsidies than in the initial steady state. Since this quantity is received only while attending college, i.e. four years, it is equivalent to 134 EUR a year, being this number roughly consistent with the increase in the annual per-student education subsidy in Spain between the early 80s and 1993, which was 85.27 EUR a year. Although the higher amount of education subsides partially compensates for the fall in the wage premium and the higher taxes paid, the after-tax aftersubsidy present value of lifetime earnings is lower for all the generations of skilled individuals born after period 0 . However, in the presence of binding borrowing constraints the measure of discounted lifetime earnings may not be the most suitable measure of the well being of individuals since it does not capture the positive effect of a smoother consumption stream on individual welfare. For this reason measure (5) reports life-time utility and find that all the generations of skilled individuals born after the educational policy reform are better off by the same amount as unskilled individuals. Being this feature a result of the fact that ex-ante utility is the same for both types of agents.

However these benefits come at a cost. The first part of this cost is related to the evolution of the social security tax rate. Notice that although all individuals born in the period of the policy reform and over are better off in terms of utility, those born in the initial periods of the transition attain higher utility than those individuals born in the periods of high social security tax rates (period 5 and over). In particular, although over the initial periods of the transition the social security tax rate slightly falls, after the third period of the transition it increases by almost five percentage points by period 6 inducing a financial loss of 6500 EUR and 3430 EUR to skilled and unskilled workers born that period.

On the other hand, the government has to rise income taxes to finance the increase in ed- 
ucation subsidies. The higher income taxes reduce the discounted lifetime earnings of all individuals of the economy. For instance, skilled and unskilled individuals born in period 0 loose 2040 EUR and 965 EUR respectively. In addition, most of the individuals already living at the period of the policy reform suffer a loss in utility. In particular, by generations, the first feature one can observe is that generation -4 and -3 are worse off since they are taxed (through capital income taxation) in order to finance education subsidies. Notice also that the utility of generation -3 is even more reduced since they face higher income taxes over two model periods. In addition, skilled workers face higher welfare losses since they are also affected by a reduction in the maximum pension they get since the average wage bill declines in the first period of the transition. Absent any change in income and social security taxes, unskilled agents of generation -2 are financially better off (in terms of the discounted lifetime earnings) as compared to the initial steady state. The reason is that in the period of the reform (period 0) there is an increase in the unskill wage which allows unskilled workers to increase their labor earnings not only over the working period but also on retirement since they now qualify for higher social security benefits. In particular, these individuals gain 55 EUR. The opposite happens to skilled workers. In particular, they loose 231 EUR with the educational reform. After adding the effect of income and social security taxes, the skilled workers of generation -2 end up with a financial loss of 1343 EUR and the unskilled ones with a loss of 387 EUR. These results are also confirmed in terms of lifetime utility.

With respect to generation -1 it is worth noting that the main mechanism that affects the financial position of individuals is the fall of the wage premium. Notice that without the effect of income and social security taxes, skilled agents loose 8772 EUR while unskilled ones gain 2451 EUR in their discounted value of earnings. Adding the increase in the income tax rate and the lower social security taxes over the initial periods on the transition only exacerbates these numbers which are consistent with the results in terms of utility.

Summarizing the results, the increase in the percentage of GNP spent on subsidizing education has benefits in the form of an smoother consumption profile for skilled individuals born at the period of the policy reform and over, and in the form of higher earnings for unskilled ones, due to the fall in the skill premium. The generations of skilled and unskilled 
individuals that benefit more from such reform are those born in the initial periods of the transition. On the cost side, the implied increase in income taxes needed to finance the educational reform reduces the earnings of individuals, although the loss of utility associated with this fact damage relatively more to those individuals already living when the reform is implemented. In addition, the increase in the social security tax rate from the third period of the transition and over (due to the induced aging process and the retirement of the better educated generations) reduces considerably the benefits of the educational reform for those generations of individuals born in these periods.

\subsection{The role of the Demographic Change}

In the previous section, part of the cost associated to the increase of education subsidies came from the increase in the social security tax rate induced by the aging of the population. This process is caused by the increase of the share of the population (the educated one) with higher life expectancy and lower fertility. In order to further analyze the contribution of this mechanism to the evaluation of the quantitative costs of education subsidies, I have perform the same policy experiment but keeping constant the initial age structure of the population. Consequently, although individuals choose optimally consumption and fertility, the model abstracts from the demographic change and consequently we disregard any change in the population. The results are shown in Table 6, 7 and 8. This experiment displays a similar pattern in terms of the dynamic behavior of the skill proportion of the population and the wage premium. For instance, in this case the proportion of skilled individuals increases from an initial value of $20.66 \%$ to a maximum value $30.31 \%$ in period 4 of the transition and then reaches a value $30.24 \%$ in the new steady state. Despite this similarity, this experiment has a number of salient features that are worth noting. They are concerned with the different behavior of the social security tax rate and its implications for the well being of agents in terms of the discounted earnings and utility. In particular, the social security tax rate slightly decreases over the initial periods of the transition, then increases up to a maximum level $30.14 \%$ in period 7 of the transition and then reaches a long run value of $30.12 \%$. These numbers are substantially more moderate than the ones in the model that accounts for the 
change in the structure of the population. The effect of this different pattern translates into a lower cost associated with the educational reform since now those individuals born in the period of the policy reform and over escape from the burden associated to the higher social security tax rates induced by the aging of the population and in comparison with the baseline policy experiment they are better off both in terms of the discounted earnings and utility.

\subsection{Partial Equilibrium Analysis}

The above calculations incorporate the general equilibrium effects of the increase in education subsidies associated with the fall of the wage premium as a higher proportion of the population decides to attend college. This effect is expected to reduce the incentives to become skilled and the cost of the policy reform in terms of the lower burden of taxation. To further understand to what extent it is convenient to analyze the effect of the policy experiment in a general equilibrium framework in which agents take account of the change in the wage premium, in this section I present the results of the increase in education subsidies holding constant the wages at the level of the initial steady state (see Table 9). Notice that, absent any change in relative wages, the incentives to acquire human capital are now higher and consequently there is a jump in the equilibrium share of skilled individuals over the transition between steady states. As happened in the baseline experiment, in the initial period of the transition, the increase in the college enrolment translates into a temporary decrease in the number of hours worked, which pushes down average earnings and slightly increases the social security tax rate in the first period of the transition. As the proportion of skilled individuals increases, the fall in average fertility and the induced demographic change is more relevant and consequently the social security tax rate that balances the pension budget is much higher than in the benchmark policy experiment that incorporates general equilibrium effects. The differences between the two cases are quantitatively relevant. For instance, in the partial equilibrium case the proportion of skilled individuals increases from $20.66 \%$ in the initial steady state to $41.66 \%$ in the first period of the transition and $41.94 \%$ in the third one. The proportion of the population attending college in the final steady state is $43.74 \%$. Similarly, the dependency ratio also experiences a more important increase from 0.194 in the initial steady state to 0.219 
in the final one. Finally, the social security tax rate increases from $29.91 \%$ to $33.62 \%$ in the final steady state, although over the transition between steady states this tax rate reaches values of almost $40 \%$ by period 6 of the transition.

Finally, it is also interesting to analyze the performance of the model when keeping constant not only wages but also the savings of the initial steady state. The results are even more pronounced since we abstract from the reduction of savings induced by the higher burden of taxation. In this case, given the increase of the income tax, the tax receipts that the government redistributes in the form of higher education subsidies to skilled individuals, would yield the result of all the individuals of the population attending college. In the same fashion, the long run dependency ratio and the social security tax rate would be 0.296 and $43.2 \%$. These results show the relevance of performing policy experiments in a general equilibrium framework.

\section{$5 \quad$ Other Experiments}

As mentioned in the last section, the increase in the percentage of GNP spent on subsidizing higher education alone was not able to account for the real increase in the enrolment rate at universities from the 80 s to the 90 s in Spain. In this section I explore two additional mechanisms that can help to reconcile the predictions of the model with the data. The two mechanism are an episode of skill biased technical change and an improvement of the life expectancy in favor of individuals with college education.

\subsection{The Role of Skill Biased Technical Change and Life Expectancy}

The policy experiment of this section is to ask how much does the model improve in predicting the actual change in the enrolment rate at universities between 1980 and 1995, when in addition to the increase in education subsidies, the model economy is also affected by a technological improvement in favor of skilled labor. The implementation of this technical improvement is implemented following Heckman, Lochner and Taber (1998). Their model economy starts from an initial steady state and then by the mid 70s technology begins to manifests a skill biased. In particular, for the US economy they estimate that for an elasticity 
of substitution $(1 / \rho) 1.441$, the $\log ((1-\gamma) / \gamma)$ declines linearly at $3.6 \%$ per year, starting in the mid 70s and continuing for 30 years. They also find that when the elasticity of substitution is lower (1.186) then the estimated time trend is higher (4.1\% per year). Given that the elasticity of substitution used my paper is higher $(1 / \rho=4)$ than in that study, I assume that the technology starts improving in 1980 so that the $\log ((1-\gamma) / \gamma)$ declines linearly at $1 \%$ per year over a period of 15 years. Consequently in $1980 \gamma=0.615$ and in $1995 \gamma=0.647$. From 1995 and over I assume that $\gamma$ remains constant at 0.647 .

The results indicate that now the model economy performs better in matching the change of the enrolment in college education in the data from $21 \% 1980$ to $45 \%$ in 1995 . In particular in the model economy the initial value is $20.66 \%$ and in the first period of the transition which corresponds to 1995, this proportion increases up to $43.09 \%$. The wage premium increases from 2.2181980 to 2.541 in 1995 and then decreases until it settles down in a value 1.989.

An additional mechanism that can generate an increase in the proportion of the population that attends college is an improvement of life expectancy in favor of educated individuals, although it is expected that any realistic improvement of this matter does not induce a quantitatively relevant increase in the incentives to acquire human capital. In particular, I consider the effect of adding an improvement in life expectancy of 4 and 2 years for skilled and unskilled individuals respectively over a period of 15 years starting in $1980^{1}$. The effect of considering this additional mechanism (see Table 10) is to fully account for the enrolment rate in college education in 1995. In particular, in the model economy the enrolment in universities increase from $20.66 \%$ in 1980 to $46.40 \%$ in 1995 , while in the data the variation is from $21 \%$ to $45 \%$. Regarding the evolution of the wage premium the model economy predicts an increase from 2.21 in 1980 to 2.53 in 1995. These numbers are roughly consistent with the recent evidence for Spain provided by Bover, Bentolila and Arellano (2000), who provide evidence that supports the view that the ratio of monthly wages between college graduates and the average of those individuals without university education has moved from 2.49 in 1980 to 2.62 in 1987.

\footnotetext{
${ }^{1}$ In Eurostat Demographic Statistics 1996, it is reported that from 1960 to 1995 life expectancy at birth has increased 8 years in Spain.
} 


\subsection{A Lower Legal Replacement Ratio}

In the last section the social security is calibrated to capture the main feature of the Spanish Social Security System in 1980. In particular, pension benefits are computed applying a legal replacement rate to the average of earnings of the five years before retirement. This replacement rate is $100 \%$ if a worker has contributed more than 35 years to the system. Since this legal replacement rate is somehow not very common in western countries, to have an idea of what would be the effect of subsidizing education on the sustainability of a pay-as-you-go system with an alternative replacement rate I proceed as follows. I consider an alternative initial steady state where pensions are computed applying a $70 \%$ replacement rate over the average earnings of the last 5 years before retirement. It is found that given this replacement rate the model economy matches the same enrolment rate in higher education as in the initial steady state of the previous experiment. The rest of parameters of the model economy and the educational reform analyzed in the last section are the same.

In this model economy (see Table 11) the initial tax rate that balances the social security system (25.60\%) is lower than in the previous experiment (29.91\%) since the pension level to which agents qualify is lower. We find that in this experiment an increase in the percentage of GNP spent in education subsidies yields very similar results concerning the evolution of the proportion of skilled agents and relative wages. Finally, the change in the age structure of the population is similar to the baseline experiment since the change of the enrolment in higher education is also similar.

\section{Concluding Remarks}

This paper has analyzed the quantitative effects of subsidizing education on the financial sustainability of the social security system in a general equilibrium model where individuals are allowed to choose fertility and their educational attainment. The increase in the percentage of GNP spent on higher education has been substantial across developed countries. This fact and the expected increase in the proportion of retirees over the working population from 2025 to 2050 seems to justify the study of both phenomena since as it is shown in the paper, 
the later may well be a consequence of the former. In this sense, it is shown that when this interaction is taken into account, the efficiency gains of education subsidies are substantially lower since these also rise the social security tax rate needed to balance the pension budget. The reason is the change of the age structure of the population induced by the change in the educational attainment of that population.

There are several ways in which the present analysis could be extended. On the one hand, this paper considers only one way in which individuals can take advantage from public expenditure on education (through education subsidies). It would be useful to investigate alternative ways in which public expenditure may increase the willingness of agents to attend college. On the other hand, the demographic change generated by the model is the result of a change in the educational composition of the population and the fertility decisions, taking as given the timing of reproduction. However, it is very likely that the demographic change in the data has also been generated by endogenous changes in the fertility timing behavior of agents. For this reason, a more sophisticated version of the model should consider the timing fertility decisions as an endogenous variable of the agent's problem e.g. Conesa (2000). This not only would help to improve the demographic change that the model predicts but also would shed additional light on the real increase in taxation needed to keep working the existing pay-as-you-go social security systems in western economies. 


\section{References}

[1] Auerbach and Kotlikoff (1987). Dynamic Fiscal Policy. Cambridge University Press.

[2] Barro, R., Becker, G. (1989), "Fertility Choice in a Model of Economic Growth", Econometrica $5 \%$.

[3] Becker,G., Murphy, M., Tamura, R.,(1990), "Human capital, Fertility, and Economic Growth", Journal of Political Economy 98.

[4] Blomm, Kaganovich, M., "Distributional Effects of Public Education in an Economy with Public Pensions", forthcoming in International Economic Review.

[5] Bover, O. Bentolila, S., Arellano, M. (2000) "The Distribution of Earnings in Spain during the 1980s: The Effect of Skill, Unemployment, and Union Power", Working Paper n. 0015, Bank of Spain-Research Department.

[6] Canova, F., Ravn, M.O., (1997), "Crossing the Rio Grande: Migrations, Business Cycle and the Welfare State", unpublished manuscript, Universitat Pompeu Fabra.

[7] Conesa, J.C. (2000), "Educational Attainment and Timing of Fertility Decisions", unpublished manuscript, Universitat de Barcelona and CREB.

[8] Cubeddu, Luis (1996), "The Intra-Generational Redistributive Effects of Social Security", Universitat Pompeu Fabra, Economics Working Papers no 168.

[9] F. Denton, B. Spencer (1988), Endogenous vs. Exogenous Fertility: What Difference for the Macroeconomy?. in, Economics of Changing Age Distributions in Developed Countries (R. Lee, W. Arthur, G. Rodgers Eds.), pp. 183-209, Clarendon Press. Oxford.

[10] Docquier, F., Michel, F. "Education Subsidies, Social Security and growth: The implications of a demographic shock", Scandinavian Journal of Economics. 101(3), September 1999, pages 425-40.

[11] Ehrlich, I., Lui, F. (1998) "Social Security, the Family and Economic Growth". Economic Inquiry. Vol. XXXVI, July 1998, 390-409. 
[12] Franco, D.; Munzi, T. (1996) "Public pension expenditure prospects in the European Union: A survey of national protections", in European Economy, No 3, pag. 126, European Commission.

[13] Freeman, R. (1987), "Demand Elasticities for educated labor" in Psacharopoulos, G. (Ed.) Economics of Education: Research and Studies. New York, Pergamon Press.

[14] Heckman, J. J., Lochner, L., Taber, C. (1998) "Explaining Rising Wage Inequality: Explorations with a Dynamic General Equilibrium Model of Labor Earnings with Heterogeneous Agents", Review of Economic Dynamics 1, 1-58.

[15] Heckman, J. J., Lochner, L., Taber, C. (1999) "General Equilibrium Cost Benefit Analysis of Education and Tax Policies", National Bureau of Economic Research, Working Paper 6881.

[16] Huang, Imrohoroglu and Sargent (1997). "Two Computations to Fund Social Security", Macroeconomic Dynamics 1, 7-44.

[17] Hurd, M.A. (1989). "Mortality risks and bequests", Econometrica, 57 (4), 779-813.

[18] Imrohoroglu, S., Imrohoroglu and D. Jones (1995). "A Life Cycle Analysis of Social Security", Economic Theory 6, 83-114.

[19] Kaganovich, M., Zilcha, I., (1999). "Education, Social Security and Growth", Journal of Public Economics. 71(2), February 1999, pages 289-309.

[20] Puch, L., Licandro, O. "Are there any special features in the Spanish business cycle?". Investigaciones Economicas, volume XXI (2)-May 1997.

[21] Ringen, S. (1991). "Households, Standard of Living, and Inequality", Review of Income and Wealth, 37 .

[22] Rios-Rull, Jose-Victor,(1993) "Working in the Market, Working at Home, and the Acquisition of Skills: A General Equilibrium Approach", American Economic Review, Sep. 1993. 
[23] Rios-Rull, J.V. (2001), "Population Changes and Capital Accumulation: The Aging of the Baby Boom", Advances in Macroeconomics; 1(1), 2001. 
Table 1: Average fertility rate in Spain

\begin{tabular}{lcccccc}
\hline \hline Year & 1950 & 1965 & 1975 & 1980 & 1995 & 2001 \\
\hline Fertility & 2.5 & 3.0 & 2.8 & 2.3 & 1.1 & 1.2 \\
\hline \hline
\end{tabular}

Source: Instituto Nacional de Estadistica 2003.

Table 2: Demographics of the Spanish and the Model economy

\begin{tabular}{lcc}
\hline \hline & Spain & Model (Replacement rate 100\%) \\
Age Group & 1980 & Initial S.S. \\
\hline $0-14$ & 25.64 & 33.49 \\
$15-29$ & 23.24 & 24.74 \\
$30-44$ & 17.93 & 18.07 \\
$45-59$ & 17.60 & 12.85 \\
$60-74$ & 11.39 & 8.06 \\
+75 & 4.20 & 2.79 \\
\hline \hline
\end{tabular}


Table 3: Baseline Experiment: Effects of the Educational Reform. Legal replacement rate $100 \%$.

\begin{tabular}{c|ccccccc}
\hline \hline \multirow{2}{*}{ Period } & $\begin{array}{c}\text { Skilled } \\
\text { agents in } \%\end{array}$ & $w_{s} / w_{u}$ & $\begin{array}{c}\text { Dependency } \\
\text { ratio } \\
+60 /(15-59)\end{array}$ & $\begin{array}{c}\text { Avergare } \\
\text { fertility }\end{array}$ & $\begin{array}{c}\text { Fertility } \\
\text { rate } \\
\text { Skilled }\end{array}$ & $\begin{array}{c}\text { Fertility } \\
\text { rate } \\
\text { Unskilled }\end{array}$ & $\begin{array}{c}\text { soc. sec. } \\
\text { tax }(\%)\end{array}$ \\
\hline-1 & 20.66 & 2.218 & 0.194 & 1.354 & 0.901 & 1.471 & 29.91 \\
0 & 31.13 & 2.214 & 0.194 & 1.321 & 0.903 & 1.510 & 30.07 \\
1 & 30.09 & 2.037 & 0.194 & 1.277 & 0.910 & 1.435 & 28.25 \\
2 & 29.74 & 1.948 & 0.196 & 1.242 & 0.911 & 1.382 & 27.37 \\
3 & 30.48 & 1.960 & 0.204 & 1.292 & 0.942 & 1.445 & 30.33 \\
4 & 31.41 & 1.951 & 0.218 & 1.328 & 0.969 & 1.492 & 32.45 \\
5 & 31.38 & 1.934 & 0.228 & 1.356 & 0.991 & 1.522 & 33.84 \\
6 & 31.32 & 1.927 & 0.227 & 1.369 & 1.002 & 1.537 & 34.28 \\
$\ldots$ & & & & & & & \\
$\infty$ & 30.69 & 1.943 & 0.207 & 1.324 & 0.968 & 1.482 & 31.71 \\
& & & & & & & \\
\hline \hline
\end{tabular}

Notes. Period -1 is the initial steady state (1980) and period 0 is the period in which the educational policy reform is implemented. 
Table 4: Baseline Experiment: Discounted Lifetime Earnings (Thousands of 1980 Euros) and Utility of Skilled agents by cohort.

\begin{tabular}{l|ccccc}
\hline \hline & Earnings & $(1)$ with & $(2)$ with & $(3)$ with & Utility \\
& Base Tax & $\begin{array}{c}\text { new income } \\
\text { tax }\end{array}$ & $\begin{array}{c}\text { new soc. sec. } \\
\text { tax }\end{array}$ & $\begin{array}{c}\text { new education } \\
\text { subsidy }\end{array}$ \\
\hline Cohort & $(1)$ & $(2)$ & $(3)$ & $(4)$ & $(5)$ \\
\hline-6 & 268.109 & 268.109 & 268.109 & 268.109 & -22.150 \\
-5 & 268.109 & 268.109 & 268.109 & 268.109 & -22.150 \\
-4 & 268.109 & 268.109 & 268.109 & 268.109 & -22.150 \\
-3 & 268.109 & 268.109 & 268.109 & 268.109 & -22.150 \\
-2 & 267.878 & 266.964 & 266.766 & 266.766 & -22.159 \\
-1 & 259.337 & 257.238 & 258.946 & 258.946 & -22.214 \\
0 & 250.882 & 248.842 & 254.438 & 254.977 & -22.061 \\
1 & 249.345 & 247.331 & 250.844 & 251.444 & -22.037 \\
2 & 249.282 & 247.266 & 243.718 & 244.370 & -22.048 \\
3 & 248.309 & 246.299 & 237.756 & 238.422 & -22.106 \\
4 & 247.620 & 245.617 & 234.366 & 235.041 & -22.140 \\
5 & 247.598 & 245.596 & 235.196 & 235.853 & -22.145 \\
6 & 247.996 & 245.991 & 239.400 & 240.026 & -22.131 \\
7 & 248.613 & 246.605 & 243.426 & 244.037 & -22.100 \\
$\infty$ & 248.533 & 246.523 & 242.000 & 242.629 & -22.089 \\
\hline \hline
\end{tabular}

Notes. Generation 0 refers to individuals born in the period of the policy reform. Column (1) reports the after-tax lifetime earnings (in thousands of 1980 euros), using the taxes and education subsidies of the initial steady state. The interest rate used to discount earnings is the after-tax interest rate of the initial steady state. (2) adds the effect of the new income tax, column (3) adds the effect of the new social security tax rate, column (4) adds the effect of the new education subsidies and (5) reports lifetime utility. 
Table 5: Baseline Experiment: Discounted Lifetime Earnings (Thousands of 1980 euros) and Utility of Unskilled agents by cohort.

\begin{tabular}{|c|c|c|c|c|c|}
\hline & $\begin{array}{l}\text { Earnings } \\
\text { Base Tax }\end{array}$ & $\begin{array}{c}\text { (1) with } \\
\text { new income } \\
\text { tax }\end{array}$ & $\begin{array}{c}\text { (2) with } \\
\text { new soc. sec. } \\
\text { tax }\end{array}$ & $\begin{array}{l}\text { (3) with } \\
\text { ew education } \\
\text { subsidy }\end{array}$ & Utility \\
\hline Cohort & (1) & $(2)$ & (3) & (4) & $(5)$ \\
\hline-6 & 111.287 & 111.287 & 111.287 & 111.287 & -22.150 \\
\hline-5 & 111.287 & 111.287 & 111.287 & 111.287 & -22.150 \\
\hline-4 & 111.287 & 111.287 & 111.287 & 111.287 & -22.151 \\
\hline-3 & 111.287 & 111.287 & 111.287 & 111.287 & -22.151 \\
\hline-2 & 111.342 & 110.979 & 110.900 & 110.900 & -22.161 \\
\hline-1 & 113.738 & 112.875 & 113.620 & 113.620 & -22.105 \\
\hline 0 & 116.452 & 115.487 & 117.944 & 117.944 & -22.061 \\
\hline 1 & 117.210 & 116.233 & 117.979 & 117.979 & -22.037 \\
\hline 2 & 117.370 & 116.392 & 115.045 & 115.045 & -22.048 \\
\hline 3 & 117.739 & 116.759 & 112.853 & 112.853 & -22.106 \\
\hline 4 & 118.032 & 117.049 & 111.680 & 111.680 & -22.140 \\
\hline 5 & 118.070 & 117.086 & 111.960 & 111.960 & -22.145 \\
\hline 6 & 117.918 & 116.935 & 113.506 & 113.506 & -22.131 \\
\hline 7 & 117.664 & 116.683 & 114.946 & 114.946 & -22.100 \\
\hline$\infty$ & 117.674 & 116.693 & 114.510 & 114.510 & -22.089 \\
\hline
\end{tabular}

Notes. Generation 0 refers to individuals born in the period of the policy reform. Column (1) reports the after-tax lifetime earnings (in thousands of 1980 euros), using the taxes and education subsidies of the initial steady state. The interest rate used is the after-tax interest rate of the initial steady state. (2) adds the effect of the new income tax, column (3) adds the effect of the new social security tax rate, column (4) adds the effect of the new education subsidies and (5) reports lifetime utility. 
Table 6: Experiment with Fixed Population Structure: Effects of the Educational Reform. Legal replacement rate $100 \%$.

\begin{tabular}{c|ccccccc}
\hline \hline \multirow{2}{*}{ Period } & $\begin{array}{c}\text { Skilled } \\
\text { agents in } \%\end{array}$ & $\begin{array}{c}w_{s} / w_{u} \\
\text { Dependency } \\
\text { ratio } \\
+60 /(15-59)\end{array}$ & $\begin{array}{c}\text { Avergare } \\
\text { fertility }\end{array}$ & $\begin{array}{c}\text { Fertility } \\
\text { rate } \\
\text { Skilled }\end{array}$ & $\begin{array}{c}\text { Fertility } \\
\text { rate } \\
\text { Unskilled }\end{array}$ & $\begin{array}{c}\text { soc. sec. } \\
\text { tax }(\%)\end{array}$ \\
\hline-1 & 20.66 & 2.218 & 0.194 & 1.354 & 0.901 & 1.471 & 29.91 \\
0 & 31.00 & 2.214 & 0.194 & 1.322 & 0.903 & 1.510 & 30.06 \\
1 & 30.05 & 2.040 & 0.194 & 1.278 & 0.910 & 1.437 & 28.28 \\
2 & 29.74 & 1.951 & 0.194 & 1.245 & 0.912 & 1.385 & 27.38 \\
3 & 30.20 & 1.963 & 0.194 & 1.286 & 0.937 & 1.438 & 29.67 \\
4 & 30.31 & 1.960 & 0.194 & 1.297 & 0.945 & 1.450 & 30.19 \\
5 & 30.23 & 1.954 & 0.194 & 1.292 & 0.943 & 1.444 & 30.00 \\
6 & 30.23 & 1.954 & 0.194 & 1.293 & 0.944 & 1.445 & 30.07 \\
$\ldots$. & & & & & & & \\
$\infty$ & 30.24 & 1.955 & 0.194 & 1.294 & 0.944 & 1.446 & 30.12 \\
\hline \hline
\end{tabular}

Notes. Period -1 is the initial steady state (1980) and period 0 is the period in which the educational policy reform is implemented. 
Table 7: Experiment with Fixed Population: Discounted Lifetime Earnings (thousands of 1980 Euros) and Utility of Skilled agents by cohort.

\begin{tabular}{l|ccccc}
\hline \hline & Earnings & $(1)$ with & $(2)$ with & $(3)$ with & Utility \\
& Base Tax & new income & new soc. sec. & new education & \\
& & tax & tax & subsidy & \\
\hline Cohort & $(1)$ & $(2)$ & $(3)$ & $(4)$ & $(5)$ \\
\hline-6 & 268.109 & 268.109 & 268.109 & 268.109 & -22.150 \\
-5 & 268.109 & 268.109 & 268.109 & 268.109 & -22.150 \\
-4 & 268.109 & 268.109 & 268.109 & 268.109 & -22.150 \\
-3 & 268.109 & 268.109 & 268.109 & 268.109 & -22.150 \\
-2 & 267.881 & 266.967 & 266.772 & 266.772 & -22.159 \\
-1 & 259.435 & 257.336 & 259.013 & 259.013 & -22.213 \\
0 & 251.062 & 249.022 & 254.563 & 255.105 & -22.059 \\
1 & 249.578 & 247.562 & 251.831 & 252.431 & -22.030 \\
2 & 249.763 & 247.743 & 247.851 & 248.485 & -22.024 \\
3 & 249.429 & 247.411 & 246.858 & 247.481 & -22.052 \\
4 & 249.297 & 247.281 & 246.936 & 247.556 & -22.057 \\
5 & 249.329 & 247.314 & 246.796 & 247.417 & -22.056 \\
6 & 249.338 & 247.322 & 246.717 & 247.338 & -22.057 \\
7 & 249.330 & 247.315 & 246.730 & 247.350 & -22.057 \\
$\infty$ & 249.332 & 247.316 & 246.733 & 247.354 & -22.057 \\
\hline \hline
\end{tabular}

Notes. Generation 0 refers to individuals born in the period of the policy reform. Column (1) reports the after-tax lifetime earnings (in thousands of 1980 euros), using the taxes and education subsidies of the initial steady state. The interest rate used to discount earnings is the after-tax interest rate of the initial steady state. (2) adds the effect of the new income tax, column (3) adds the effect of the new social security tax rate, column (4) adds the effect of the new education subsidies and (5) reports lifetime utility. 
Table 8: Experiment with Fixed Population: Discounted Lifetime Earnings (Thousands of 1980 Euros) and Utility of Unskilled agents by cohort.

\begin{tabular}{l|ccccc}
\hline \hline & Earnings & $(1)$ with & $(2)$ with & $(3)$ with & Utility \\
& Base Tax & new income & new soc. sec. & new education & \\
& & tax & tax & subsidy & \\
\hline Cohort & $(1)$ & $(2)$ & $(3)$ & $(4)$ & $(5)$ \\
\hline-6 & 111.287 & 111.287 & 111.287 & 111.287 & -22.154 \\
-5 & 111.287 & 111.287 & 111.287 & 111.287 & -22.154 \\
-4 & 111.287 & 111.287 & 111.287 & 111.287 & -22.155 \\
-3 & 111.287 & 111.287 & 111.287 & 111.287 & -22.155 \\
-2 & 111.341 & 110.978 & 110.901 & 110.901 & -22.161 \\
-1 & 113.705 & 112.843 & 113.574 & 113.574 & -22.106 \\
0 & 116.384 & 115.419 & 117.849 & 117.849 & -22.059 \\
1 & 117.117 & 116.141 & 118.220 & 118.220 & -22.030 \\
2 & 117.178 & 116.201 & 116.498 & 116.498 & -22.024 \\
3 & 117.287 & 116.310 & 116.085 & 116.085 & -22.052 \\
4 & 117.344 & 116.366 & 116.183 & 116.183 & -22.057 \\
5 & 117.340 & 116.362 & 116.120 & 116.120 & -22.056 \\
6 & 117.337 & 116.359 & 116.071 & 116.071 & -22.057 \\
7 & 117.339 & 116.361 & 116.076 & 116.076 & -22.057 \\
$\infty$ & 117.338 & 116.360 & 116.078 & 116.078 & -22.057 \\
\hline \hline
\end{tabular}

Notes. Generation 0 refers to individuals born in the period of the policy reform. Column (1) reports the after-tax lifetime earnings (in thousands of 1980 euros), using the taxes and education subsidies of the initial steady state. The interest rate used is the after-tax interest rate of the initial steady state. (2) adds the effect of the new income tax, column (3) adds the effect of the new social security tax rate, column (4) adds the effect of the new education subsidies and (5) reports lifetime utility. 
Table 9: Experiment with Fixed Wages: Effects of the Educational Reform. Legal replacement rate $100 \%$.

\begin{tabular}{c|ccccccc}
\hline \hline \multirow{2}{*}{ Period } & $\begin{array}{c}\text { Skilled } \\
\text { agents in } \%\end{array}$ & $w_{s} / w_{u}$ & $\begin{array}{c}\text { Dependency } \\
\text { ratio } \\
+60 /(15-59)\end{array}$ & $\begin{array}{c}\text { Avergare } \\
\text { fertility }\end{array}$ & $\begin{array}{c}\text { Fertility } \\
\text { rate } \\
\text { Skilled }\end{array}$ & $\begin{array}{c}\text { Fertility } \\
\text { rate } \\
\text { Unskilled }\end{array}$ & $\begin{array}{c}\text { soc. sec. } \\
\text { tax }(\%)\end{array}$ \\
\hline-1 & 20.66 & 2.218 & 0.194 & 1.354 & 0.901 & 1.471 & 29.91 \\
0 & 41.66 & 2.218 & 0.194 & 1.261 & 0.919 & 1.505 & 30.23 \\
1 & 41.94 & 2.218 & 0.194 & 1.198 & 0.879 & 1.428 & 26.61 \\
2 & 42.32 & 2.218 & 0.200 & 1.148 & 0.847 & 1.368 & 24.53 \\
3 & 43.91 & 2.218 & 0.218 & 1.229 & 0.907 & 1.482 & 30.46 \\
4 & 45.52 & 2.218 & 0.250 & 1.319 & 0.973 & 1.610 & 35.68 \\
5 & 45.39 & 2.218 & 0.269 & 1.385 & 1.020 & 1.691 & 38.71 \\
6 & 44.78 & 2.218 & 0.264 & 1.427 & 1.041 & 1.743 & 39.58 \\
$\ldots .$. & & & & & & & \\
$\infty$ & 43.74 & 2.218 & 0.219 & 1.302 & 0.952 & 1.572 & 33.62 \\
\hline \hline
\end{tabular}

Notes. Period -1 is the initial steady state (1980) and period 0 is the period in which the educational policy reform is implemented. 
Table 10: Experiment with Skill Biased Technical Change and Improvement in Life Expectancy: Effects of the Educational Reform. Legal replacement rate $100 \%$.

\begin{tabular}{c|ccccccc}
\hline \hline \multirow{2}{*}{ Period } & $\begin{array}{c}\text { Skilled } \\
\text { agents in } \%\end{array}$ & $\begin{array}{c}w_{s} / w_{u} \\
\text { Dependency } \\
\text { ratio } \\
+60 /(15-59)\end{array}$ & $\begin{array}{c}\text { Avergare } \\
\text { fertility }\end{array}$ & $\begin{array}{c}\text { Fertility } \\
\text { rate } \\
\text { Skilled }\end{array}$ & $\begin{array}{c}\text { Fertility } \\
\text { rate } \\
\text { Unskilled }\end{array}$ & $\begin{array}{c}\text { soc. sec. } \\
\text { tax }(\%)\end{array}$ \\
\hline-1 & 20.66 & 2.218 & 0.194 & 1.354 & 0.901 & 1.471 & 29.91 \\
0 & 46.40 & 2.539 & 0.194 & 1.310 & 0.891 & 1.672 & 31.68 \\
1 & 44.17 & 2.111 & 0.206 & 1.220 & 0.899 & 1.473 & 27.68 \\
2 & 42.19 & 1.921 & 0.212 & 1.154 & 0.895 & 1.344 & 25.88 \\
3 & 44.42 & 1.955 & 0.228 & 1.265 & 0.970 & 1.500 & 32.80 \\
4 & 47.55 & 1.942 & 0.260 & 1.350 & 1.047 & 1.625 & 37.97 \\
5 & 47.19 & 1.895 & 0.282 & 1.409 & 1.101 & 1.684 & 40.71 \\
6 & 46.32 & 1.878 & 0.276 & 1.452 & 1.131 & 1.729 & 41.51 \\
$\ldots$. & & & & & & & \\
$\infty$ & 44.71 & 1.927 & 0.225 & 1.337 & 1.030 & 1.586 & 34.91 \\
\hline \hline
\end{tabular}

Notes. Period -1 is the initial steady state (1980) and period 0 is the period in which the educational policy reform is implemented. 
Table 11: Experiment with Lower Pension Benefits: Effects of the Educational Reform. Legal replacement rate $70 \%$.

\begin{tabular}{c|ccccccc}
\hline \hline \multirow{2}{*}{ Period } & $\begin{array}{c}\text { Skilled } \\
\text { agents in } \%\end{array}$ & $\begin{array}{c}w_{s} / w_{u} \\
\text { Dependency } \\
\text { ratio } \\
+60 /(15-59)\end{array}$ & $\begin{array}{c}\text { Avergare } \\
\text { fertility }\end{array}$ & $\begin{array}{c}\text { Fertility } \\
\text { rate } \\
\text { Skilled }\end{array}$ & $\begin{array}{c}\text { Fertility } \\
\text { rate } \\
\text { Unskilled }\end{array}$ & $\begin{array}{c}\text { soc. sec. } \\
\text { tax }(\%)\end{array}$ \\
\hline-1 & 20.66 & 2.211 & 0.252 & 1.219 & 0.822 & 1.322 & 25.60 \\
0 & 31.89 & 2.207 & 0.252 & 1.180 & 0.819 & 1.350 & 25.72 \\
1 & 30.36 & 2.027 & 0.251 & 1.152 & 0.829 & 1.292 & 24.13 \\
2 & 30.38 & 1.929 & 0.255 & 1.120 & 0.833 & 1.246 & 23.33 \\
3 & 31.09 & 1.942 & 0.264 & 1.155 & 0.854 & 1.291 & 26.00 \\
4 & 31.93 & 1.932 & 0.283 & 1.179 & 0.874 & 1.322 & 27.86 \\
5 & 31.90 & 1.915 & 0.294 & 1.194 & 0.888 & 1.338 & 28.90 \\
6 & 31.78 & 1.909 & 0.296 & 1.205 & 0.897 & 1.349 & 29.43 \\
$\ldots$. & & & & & & & \\
$\infty$ & 31.31 & 1.922 & 0.275 & 1.180 & 0.876 & 1.319 & 27.66 \\
\hline \hline
\end{tabular}

Notes. Period -1 is the initial steady state (1980) and period 0 is the period in which the educational policy reform is implemented. 

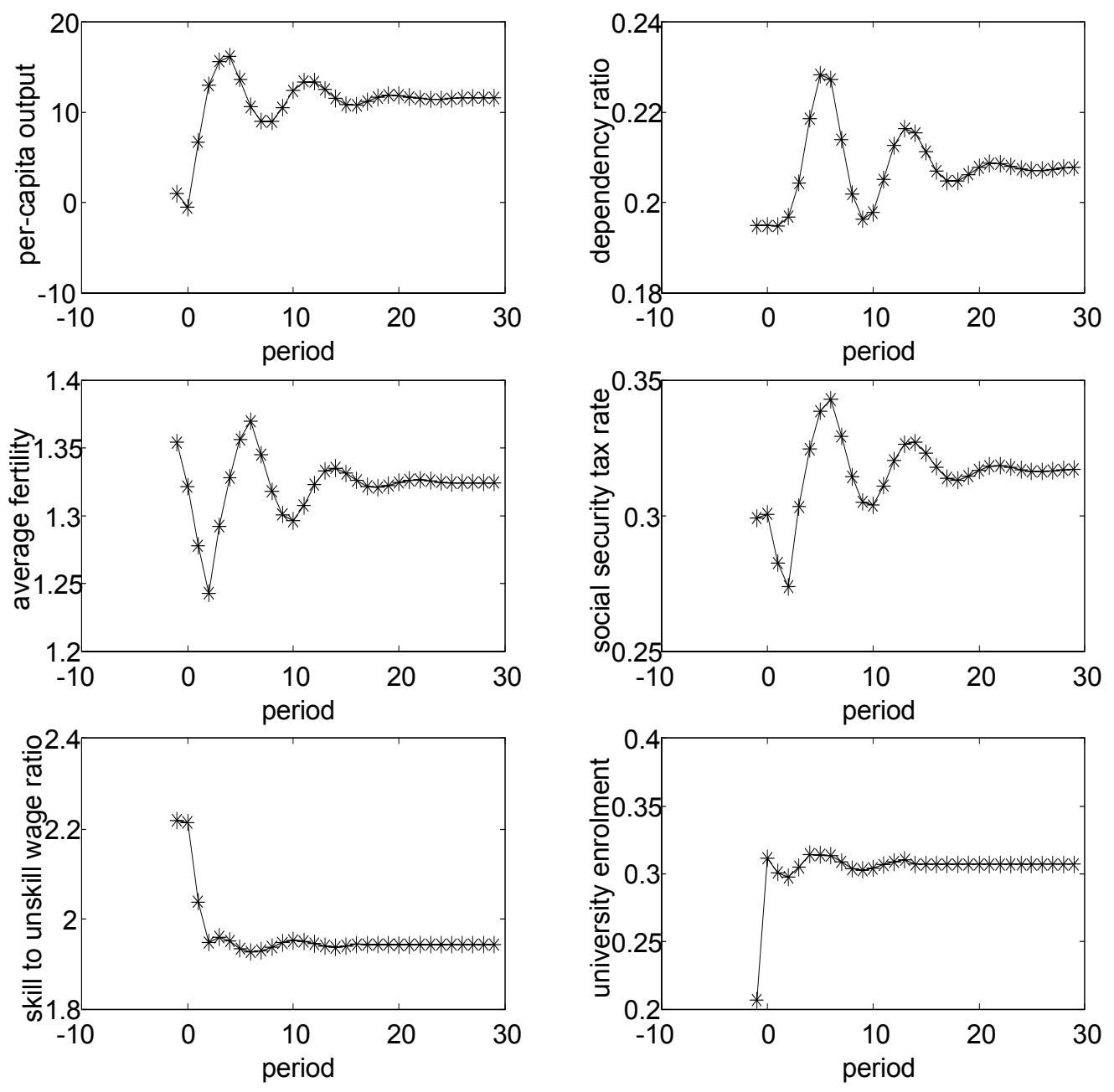

Figure 1: Baseline Experiment: An Increase in Education Subsidies. Period -1 and 0 are the initial steady state and the period of the policy reform respectively. Per-capita output is in percentage deviations from the initial steady state and the average fertility is the number of children per individual (not per women). 